\title{
Phyllotreta striolata (Coleoptera: Chrysomelidae): Arginine kinase cloning and RNAi-based pest control
}

\author{
YiYing ZHAO ${ }^{1,2}$, GUANG YANG ${ }^{1}$, GEFU WANG-PRUSKI ${ }^{3}$ and MinSHENG YOU ${ }^{1 *}$ \\ ${ }^{1}$ Institute of Applied Ecology, Fujian Agriculture and Forestry University, Fuzhou 350002, China; \\ e-mails: yiying_zhao@yahoo.com \\ ${ }^{2}$ Key Laboratory of Oasis Eco-agriculture, College of Agriculture, Shihezi University, Shihezi 832003, China \\ ${ }^{3}$ Department of Plant and Animal Sciences, Nova Scotia Agricultural College, P.O. Box 550, Truro, B2N 5E3 Nova Scotia, Canada
}

Key words. Arginine kinase, Chrysomelidae, Phyllotreta striolata, cloning, RNAi, pest control

\begin{abstract}
Insect pests cause billions of dollars in crop losses and there is the ever-present threat of insecticide resistance, pesticide pollution of food and environmental damage. New ways of controlling insect pests are urgently needed. Arginine kinase (AK) is a phosphotransferase, which plays a critical role in cellular energy metabolism in invertebrates. It only presents in invertebrates and may be a suitable chemotherapeutic target in the control of pests. In this study, we cloned and characterized the full-length AK gene from Phyllotreta striolata, one of the most destructive beetle pests worldwide. Furthermore, we constructed a dsRNA targeting AK and used RNAi to control the beetle. The feeding bioassays indicated that minute quantities of dsRNA greatly impaired the beetle's development. Ingestion of dsRNA not only significantly retarded the development and increased the mortality of adults, it also greatly reduced fecundity and fertility, suggesting that RNAi targeting AK is a potential and attractive tool for controlling insect pests.
\end{abstract}

\section{INTRODUCTION}

Arginine kinase (ATP: L-arginine phosphotransferase, EC 2.7.3.3, AK) plays a critical role in cellular energy homeostasis in invertebrates by catalyzing a reversible transfer of phosphate from $\mathrm{Mg} \cdot \mathrm{ATP}$ to arginine, yielding phosphoarginine as follows: $\mathrm{Mg} \cdot \mathrm{ATP}+$ Arginine $\Leftrightarrow$ Phosphoarginine + Mg·ADP (Newsholme et al., 1978). AK only exists in the tissues of invertebrates (e.g., gut epithelial cells, muscle fibers, and neurons) (Lang et al., 1980; Chamberlin, 1997; Kucharski \& Maleszka, 1998), and functions as a central regulator of temporal and spatial ATP buffers directly associated with muscle contraction, ATP regeneration and energy transport in cellular energy metabolism (Ellington, 2001).

$\mathrm{AK}$ is not present in vertebrates, and phosphoarginine and its biosynthetic pathway are totally different from those in mammalian tissues, indicating that AK may be a useful chemotherapeutic target in the control of pests (Pereira et al., 2000; Brown \& Grossman, 2004; Wu et al., 2007). Substrate analogs (e.g., canavanine, homoarginine) have been screened for potential enzyme inhibitors of AK (Pereira et al., 2000, 2003; Brown \& Grossman, 2004). This revealed that canavanine and homoarginine significantly inhibited Trypanosoma cruzi growth (79.7\% and 55.8\%, respectively) (Pereira et al., 2000). Canavanine can also disrupt the development of Manduca sexta (Rosenthal, 2001).

Phyllotreta striolata (Fabricius, 1803) (Coleoptera: Chrysomelidae) is one of the most serious pests of Cruciferae crops worldwide (Andersen et al., 2006). It is the most important pest of vegetable crops in Southern China and is resistant to Bacillus thuringiensis (Bt). At present, insecticide sprays are used to control $P$. striolata, which is associated with significant hazards to human and environmental health. Alternative methods of managing this highly destructive agricultural pest are therefore needed.

Eukaryotic organisms, including insects, possess an RNA interference (RNAi) mechanism for sequencespecific gene silencing that is triggered by the introduction of double-stranded RNA (dsRNA). RNAi has become a potent tool in many biological research fields ranging from identifying gene function to inhibiting viral infection (Tenllado \& Diaz-Ruiz, 2001; Tenllado et al., 2003a). Insect genes can be downregulated by microinjection of dsRNA (Bettencourt et al., 2002; Tomoyasu \& Denell, 2004; Ghanima et al., 2007) or uptake of exogenous dsRNA from an artificial diet (Turner et al., 2006). Plant-mediated strategies involving knock-down specific genes for managing pests is also recently reported (Gordon \& Waterhouse, 2007; Baum et al., 2007; Mao et al., 2007).

Genes encoding proteins with essential functions are the best RNAi targets for increasing morbidity and mortality in insects. Since AK regulates the cellular energy reserve in invertebrates, we proposed using RNAi to silence the AK gene in order to induce high mortality in insect pests. Most of the previous studies on AK focus on elucidating its catalytic mechanism and identifying its substrate analog inhibitors. This is the first attempt to employ RNAi targeting AK to control an insect pest. In this study, the AK gene from $P$. striolata was successfully

\footnotetext{
* Corresponding author; e-mail: msyou@fjau.edu.cn
} 


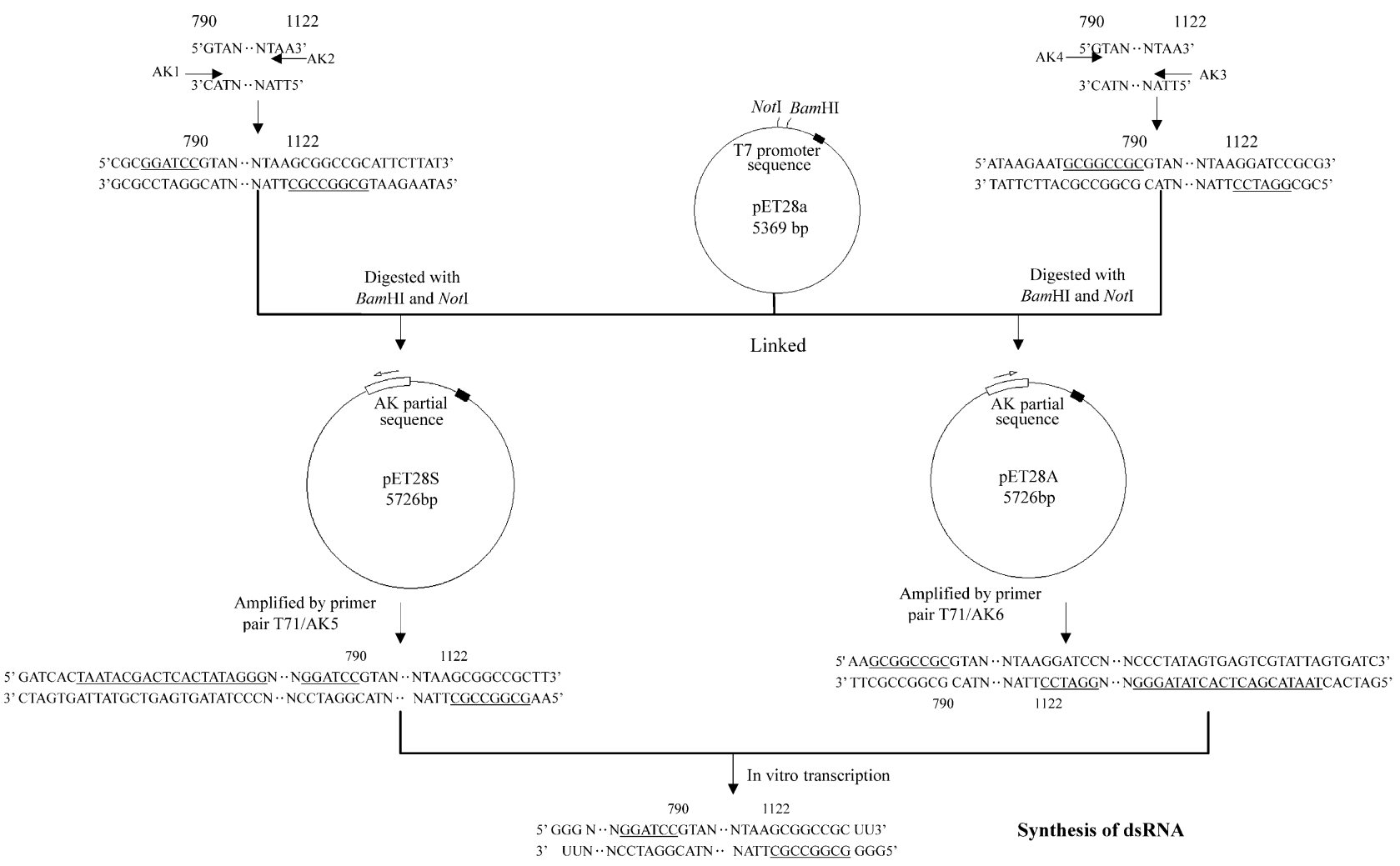

Fig. 1. The flowchart of dsRNA acquisition. AK1, a sense primer introduced with a BamHI site, corresponds to nucleotide 790 to 809 of PsAK; AK2, an antisense primer introduced with a NotI site, corresponds to nucleotide 1122 to 1103 . AK-3, a sense primer introduced with a BamHI site, corresponds to nucleotide 1122 to 1103 of PsAK; AK4, an antisense primer introduced with a NotI site, corresponds to nucleotide 790 to 809 . T7-1, a sense primer, corresponds to T7 promoter sequence of pET28S; AK5, an antisense primer, corresponds to nucleotide 790 to 809 of PsAK; AK6, the other antisense primer, corresponds to nucleotide 1122 to 1103 of PsAK. The restriction endonucleases recognition sites that are introduced into primers are underlined (BamHI recognition sequence, 5'CTCGAG3'; NotI recognition sequence, 5'GCGGCCGC3'; T7 promoter sequence, 5'TAATACGACTCACTATAGGG3').

cloned and characterized. Furthermore, the possibility of using RNAi technology to control $P$. striolata and an assessment of AK performance as a biocontrol agent for pest control were explored. RNAi provides a potential and attractive tool for controlling insect pests.

\section{MATERIAL AND METHODS}

\section{Molecular cloning}

We extracted mRNA from the whole body of beetle adults, which were reared in a growth chamber at $27^{\circ} \mathrm{C}$, a $16 \mathrm{~L}: 8 \mathrm{D}$ photoperiod and $64 \%$ relative humidity. Total RNA was extracted using RNeasy reagents (Qiagen, Hilden, Germany) and poly(A)RNA was isolated from the total RNA using E.Z.N.A mRNA Enrichment kit (Omega Bio-tek, Guangzhou, China). The cDNA was synthesized using SMART ${ }^{\mathrm{TM}}$ RACE cDNA Amplification Kit (Clontech). The 5'-half of AK gene was amplified using 5'-RACE cDNA with a universal primer A mix (UPM, Clontech, Mountain View, CA, USA) and a degenerated primer, AKR1: 5'-CYAICHTGRCCITGYTGRC-3'. This degenerated primer was designed based on the consensus sequences of AK from other insect species, including Anopheles gambiae, Bombyx mori, Drosophila melanogaster, Nasonia vitripennis, Periplaneta americana, and Tribolium castaneum. A touch down PCR was performed in which the conditions were: $5 \mathrm{~min}$ at $94^{\circ} \mathrm{C}$, then 19 cycles at $94^{\circ} \mathrm{C}$ for $50 \mathrm{~s}, 56^{\circ} \mathrm{C}$ for 1 min, and $72^{\circ} \mathrm{C}$ for $1 \mathrm{~min}$, with a decrease of the annealing temperature by $0.5^{\circ} \mathrm{C}$ per cycle. Subsequently, 19 further cycles in which the condition of the last cycling step $\left(46^{\circ} \mathrm{C}\right.$ annealing temperature) were performed followed by incubation for $10 \mathrm{~min}$ at $72^{\circ} \mathrm{C}$. The amplified products $(943 \mathrm{bp})$ were gel-purified, ligated into pMD18-T vector using TA Cloning kit (Takara, Dalian, China) and subsequently transformed into E. coli $\mathrm{DH} 5 \alpha$ competent cells. Nucleotide sequences were determined with an ABI PRISM 3730XL DNA Analyzer (Applied Biosystems, Foster City, CA, USA).

The 3' half of AK gene was amplified using 3'-RACE cDNA with a UPM and a specific primer, AKF1: 5'GTAACCGCCGTCAACGAC-3' derived from the internal sequence of $5^{\prime}$ half. PCR cycles were as follows: $94^{\circ} \mathrm{C}, 3 \mathrm{~min}$, followed by 35 cycles of $94^{\circ} \mathrm{C}$ for $50 \mathrm{~s}, 56^{\circ} \mathrm{C}$ for $1 \mathrm{~min}, 72^{\circ} \mathrm{C}$ for $1 \mathrm{~min}$, and a final cycle of $72^{\circ} \mathrm{C}$ for $10 \mathrm{~min}$. The amplified product $(719 \mathrm{bp})$ was sequenced as described above. The full length of the AK gene (1508 bp) was then amplified, subcloned, and sequenced.

\section{Sequence data processing}

The theoretical mass and isoelectric point of $P$. striolata AK (PsAK) were estimated using the ExPASy Proteomics Server (http://swissmodel.expasy.org; http://br.expasy.org/cgi-bin/pi tool). Enzyme active sites and functional residues were analyzed using Prosite software (http://www.expasy.ch/prosite/) and VMD graphic program (http://www.ks.uiuc.edu/Research/ $\mathrm{vmd} /$ ). A model of the 3D structure was constructed using the homology-modelling server SWISS-MODEL (http:// swissmodel.expasy.org/SWISS-MODEL.html) and the "First Approach Mode" was used with default settings. Multiple sequence alignment was done with Clustal X 2.0 program 


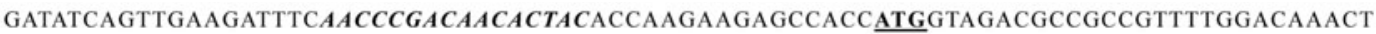

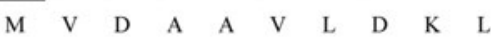
TGAATCCGGTTTCAAGAAAATCAAGGACTCCGACTCCAAATCGCTGCTGAAGAAGCACCTCACCCAGGAGATCTTCGACA

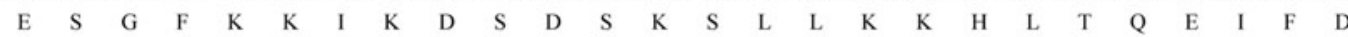
ACTTGAAGACCAAGAAGACCCCCACTTTCGGCTCGACTCTTCTTGATGTCATCCAATCCGGCTTGGAGAACCACGACTCC $\begin{array}{llllllllllllllllllllllllllllllllllllll}\mathrm{N} & \mathrm{L} & \mathrm{K} & \mathrm{T} & \mathrm{K} & \mathrm{K} & \mathrm{T} & \mathrm{P} & \mathrm{T} & \mathrm{F} & \mathrm{G} & \mathrm{S} & \mathrm{T} & \mathrm{L} & \mathrm{L} & \mathrm{D} & \mathrm{V} & \mathrm{I} & \mathrm{Q} & \mathrm{S} & \mathrm{G} & \mathrm{L} & \mathrm{E} & \mathrm{N} & \mathrm{H} & \mathrm{D} & \mathrm{S}\end{array}$ GGCGTAGGAATCTACGCCCCCGACGCTGA ATCGTACACCGTATTCGCGGACATCTTCGATCCCATCATCGAGGACTACCA

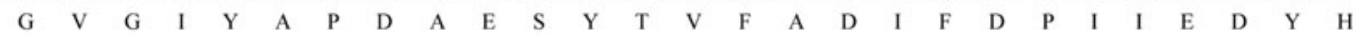
CGGCGGCTTCAAGAAGACCGACAAGCACCCGCCCAAGAACTGGGGCGACGTCAGCGTCTTCGGCGATCTCGACCCCACCG

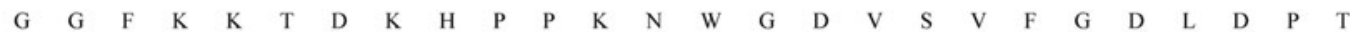
GCGAATACGTCGTCTCCACCCGCGTCAGATGCGGCCGCTCCCTGGAGGGATACCCCTTCAACCCCTGCTTGACCGAGGAC

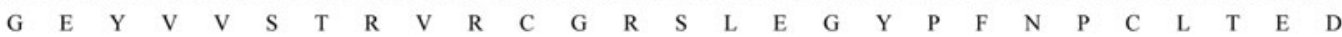
CAGTACAAGGAGATGGAGCAGAAGGTGTCCAGCACCCTCTCCGGGCTCGAAGGTGAACTCAAGGGGACCTTCTACCCGTT

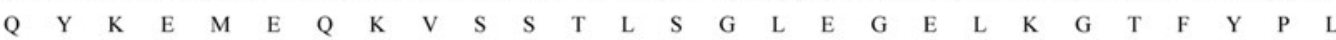
GACCGGAATGAGCAAGGACGTGCAGCAGAAGCTCATCGACGATCACTTCCTGTTCAAGGAGGGCGATCGCTTCCTGCAGG $\begin{array}{llllllllllllllllllllllllllllllllll}\mathrm{T} & \mathrm{G} & \mathrm{M} & \mathrm{S} & \mathrm{K} & \mathrm{D} & \mathrm{V} & \mathrm{Q} & \mathrm{Q} & \mathrm{K} & \mathrm{L} & \mathrm{I} & \mathrm{D} & \mathrm{D} & \mathrm{H} & \mathrm{F} & \mathrm{L} & \mathrm{F} & \mathrm{K} & \mathrm{E} & \mathrm{G} & \mathrm{D} & \mathrm{R} & \mathrm{F} & \mathrm{L} & \mathrm{Q}\end{array}$ CCGCCAACGCTTGCCGCTTCTGGCCCACCGGTCGCGGTATTTTCCACAACGACGCCAAGACCTTCTTGGTGTGGTGCAAC $\begin{array}{llllllllllllllllllllllllllllllllllllllllll}\text { A } & \text { A } & \text { N } & \text { A } & \text { C } & \text { R } & \text { F } & \text { W } & \text { P } & \text { T } & \text { G } & \text { R } & \text { G } & \text { I } & \text { F } & \text { H } & \text { N } & \text { D } & \text { A } & \text { K } & \text { T } & \text { F } & \text { L } & \text { V } & \text { W } & \text { C } & \text { N }\end{array}$ GAGGAGACCACCTTCGCATCATCTCCATGCAGATGGGAGGCGACCTGGGAGCCGTCTTCAGACGATTGGTAACCGCCGT

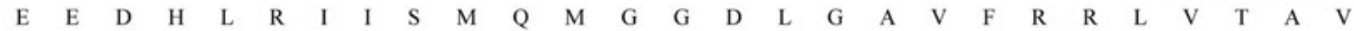
CAACGACATCGAAAAGAGACTTCCGTTCTCCCACAACGACAGGCTCGGTTTCCTGACCTTCTGCCCGACTAACTTGGGTA

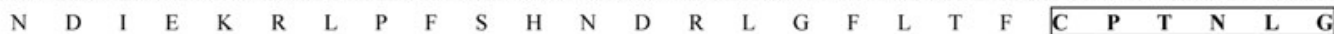
CCACTGTCCGCGCTTCGGTCCATATCAAGGTGCCCAAGTTGGCTGCCAACAAGGCCAAGCTGGAGGAGGTCGCTGCCAAG

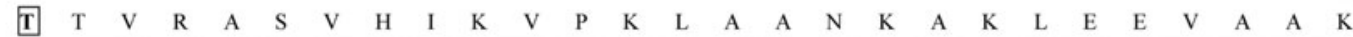
TACAACTTGCAGGTGCGCGGTACTCGCGGTGAACACACCGAGGCCGAAGGCGGTGTCTACGACATCTCCAACAAGAGACG $\begin{array}{lllllllllllllllllllllllllllllllllll}\mathrm{Y} & \mathrm{N} & \mathrm{L} & \mathrm{Q} & \mathrm{V} & \mathrm{R} & \mathrm{G} & \mathrm{T} & \mathrm{R} & \mathrm{G} & \mathrm{E} & \mathrm{H} & \mathrm{T} & \mathrm{E} & \mathrm{A} & \mathrm{E} & \mathrm{G} & \mathrm{G} & \mathrm{V} & \mathrm{Y} & \mathrm{D} & \mathrm{I} & \mathrm{S} & \mathrm{N} & \mathrm{K} & \mathrm{R} & \mathrm{R}\end{array}$ CATGGGTCTCACGGAGTTCGATGCCGTTAAGGAGATGTACGATGGCATCCAAGAAATCATTAAGATTGAAAAAGAATTGI $\begin{array}{lllllllllllllllllllllllllllllllllllll}M & G & \text { L } & \text { T } & \text { E } & \text { F } & \text { D } & \text { A } & \text { V } & \text { K } & \text { E } & \text { M } & \text { Y } & \text { D } & \text { G } & \text { I } & \text { Q } & \text { E } & \text { I } & \text { I } & \text { K } & \text { I } & \text { E } & \text { K } & \text { E } & \text { L } & *\end{array}$ AA ACGTTACAAACCCCTATATATTACATTCGTCACCATTCGTGATTTTAAAAATATATATGTAAGCGATGGTATATAAAT ATATATGTACATGTATGTATTTTACATTAAGTATCTCGTTTGCCAAAGGTATTATCGCAGATAATTGCTTTCAAAAACGC TCTGTTTGTAATTTTTAAGTTGTTGAGATAATGTCAAGTCTGAAACCCAGCTTCATTCTAGTCGACATTTTGTTTTCAAA TTTGATTTTATTTATACAAATGATGTCAAACATTGAACAATGTTACTGTATTATTTATAATTTATTTTTATTGTAATTCTGACAAATAAAAGTA TTGTTTGGAAAACACCAAAAAAACAAAAAAAAAAAAAAAAAAAAAAAAAAAAAA
\end{abstract}

Fig. 2. Complete nucleotide sequence of PsAK. The ORF extends from nucleotide 52 to 1122 and encodes a 356 amino acid protein, which is given in the single-letter code under the NT sequence. The highly conserved motif CPTNLGT (positions 271-277) is boxed and in bold. The start codon bordering the ORF is underlined and in bold. The asterisk denotes the stop codon and the polyadenylation signal (AATAAA) is double underlined and in bold. Five glyco motifs (AAYNNNAC) and three putative ribosomal binding site motifs (AGGAGG) is in bold italics. The sequence (positions 790 to 1122) containing active site motif CPTNLGT to obtain dsRNA is shaded grey. The cDNA sequence is available through GenBank, accession no. EU420057.

(http://www.clustal.org/). The distance tree was constructed with the neighbour-joining (NJ) method using MEGA 4.0 program (http://www.megasoftware.net/). Bootstrap re-sampling $(1,000$ replicates; seed $=64,238)$ was performed to assess the degree of support for the groupings on the tree.

\section{RNAi preparation}

The fragment (nucleotide 790 to 1122) of PsAK cDNA was amplified to obtain two double-stranded DNA fragments using two primer pairs AK1/AK2 and AK3/AK4 (Table 1), respec-

TABLE 1. Primers for the acquisition of dsRNA.

\begin{tabular}{cl}
\hline Primers & \multicolumn{1}{c}{ Sequences } \\
\hline AK1 & 5'-CGCGGATCCGTAACCGCCGTCAACGACAT-3' \\
AK2 & 5'-ATAAGAATGCGGCCGCTTACAATTCTTTTTCAATC-3' \\
AK3 & 5'-CGCGGATCCTTACAATTCTTTTTCAATC-3' \\
AK4 & 5'-ATAAGAATGCGGCCGCGTAACCGCCGTCAACGACAT-3' \\
T71 & 5'-GATCACTAATACGACTCACTATAGGG -3' \\
AK5 & 5'-AAGCGGCCGCTTACAATTCTTTTTCAATC-3' \\
AK6 & 5'-AA $\underline{\text { GCGGCCGCGTAACCGCCGTCAACGACAT-3' }}$ \\
\hline
\end{tabular}

The restriction endonucleases recognition sites that were introduced into the primers are underlined $(B a m H I$ recognition sequence, 5'CTCGAG3'; NotI recognition sequence, 5'GCGGCC GC3'). tively. The double-stranded DNAs, with BamHI and NotI sites introduced at the $5^{\prime}$ - or $3^{\prime}$-termini, were separately ligated into BamHI-NotI sites of expression vector pET-28a using the T7 polymerase promoter. The resulting two plasmids were named pET28S and pET28A (Fig. 1) and were later amplified using two primer pairs T7-1/AK5 and T7-1/AK6, respectively (Table 1). PCR products were used to synthesize dsRNA according to in vitro transcription T7 kit (Takara). The transcribed sense and antisense RNA were annealed to generate dsRNA after incubation for $2 \mathrm{~h}$ at $42^{\circ} \mathrm{C}$. The purified dsRNAs were quantified by spectrophotometer and examined using 1.5\% agarose gel electrophoresis to ensure their integrity. The solution for the feeding experiments was prepared by diluting dsRNA with $\mathrm{ddH}_{2} \mathrm{O}$ to varying final concentrations.

\section{Insect bioassays and statistical analysis}

P. striolata were obtained from Fujian Agriculture and Forestry University and reared in a growth chamber at $27^{\circ} \mathrm{C}$, a $16 \mathrm{~L}$ : $8 \mathrm{D}$ photoperiod and $64 \%$ relative humidity. The tissue culture seedlings of Chinese cabbage, Brassica chinensis ( $\sim 1$ week old) were transplanted into culture bottles containing sterilized fine soil. Final phase pupae of $P$. striolata were kept in an incubator until eclosion in complete darkness and $100 \%$ relative humidity. Subsequently, adult beetles, all of the same age and with a posteclosion 1: 1 sex ratio, were transferred to the above culture bottles. 


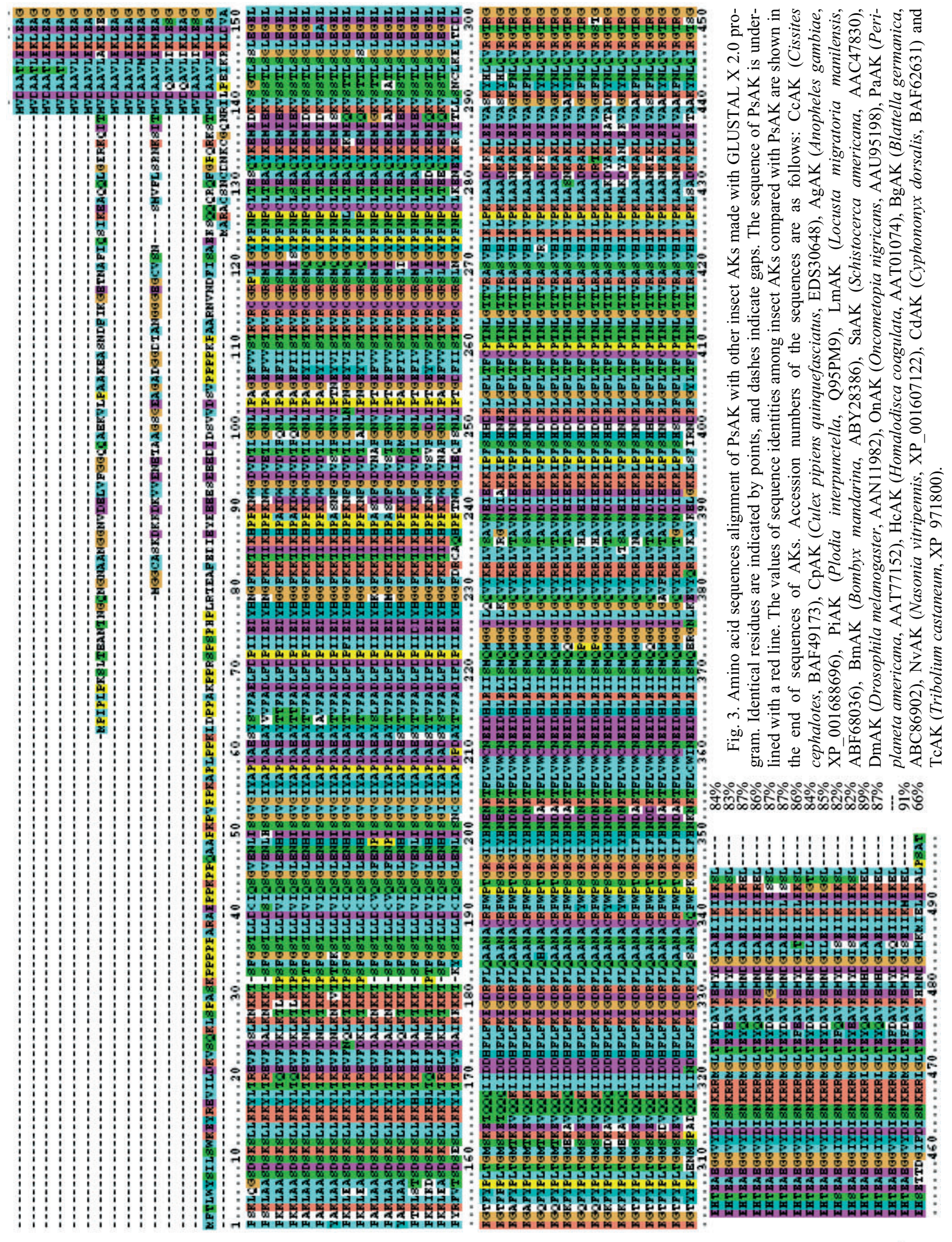

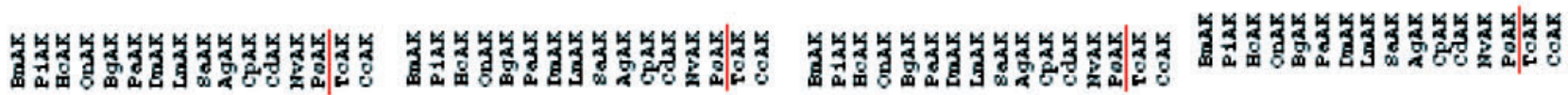




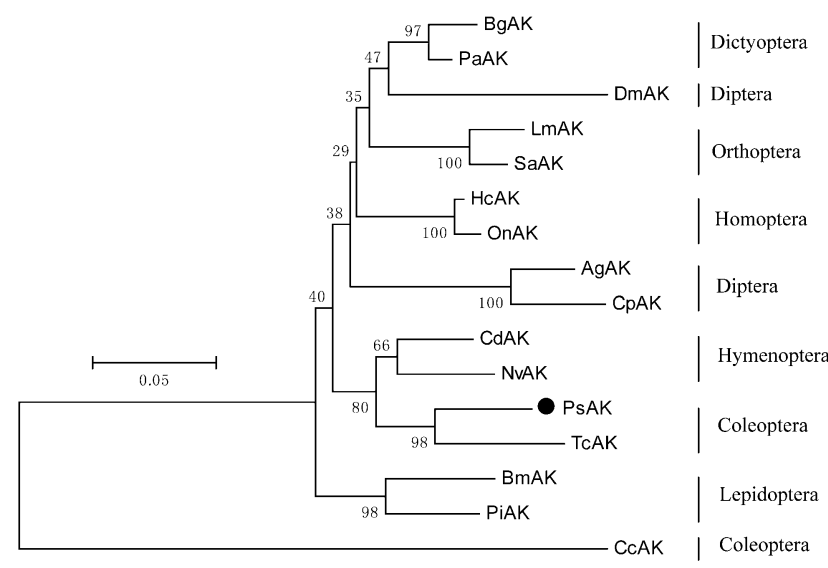

Fig. 4. A distance tree constructed by neighbour-joining method (1,000 bootstrap) for 16 amino acid sequences of insect AKs using MEGA 4.0 program. The PsAK is marked with a dot. Bootstrap values are shown at the branching point. Scale bar indicates the number of changes inferred to have occurred along each branch. Accession numbers of reference amino acid sequences used in this analysis are shown in Fig. 3.

The solutions of dsRNA of a range of dilutions $(0.05 \mathrm{ng} / \mathrm{mL}$; $0.10 \mathrm{ng} / \mathrm{mL} ; 0.20 \mathrm{ng} / \mathrm{mL} ; 0.40 \mathrm{ng} / \mathrm{mL} ; 0.80 \mathrm{ng} / \mathrm{mL} ; 1.60 \mathrm{ng} / \mathrm{mL}$; $3.20 \mathrm{ng} / \mathrm{mL}$ ) were separately sprayed onto the cotyledons and leaves of seedlings of Chinese cabbage every third day (Tenllado et al., 2003b). Twenty adult beetles of $P$. striolata were tested per dsRNA concentration. A series of dilutions of dsRNA were used in order to obtain a LC50 value, defined here as the concentration causing $50 \%$ mortality over a period of 14 days. The survival of adult beetles, number of eggs laid per female and percentage egg hatch were recorded after one month. The results were analysed statistically using the student $t$-test in the Microsoft Excel program.

\section{RT-PCR analysis}

Total RNA was isolated from the midguts of adult beetles using Qiagen RNeasy Mini kit and then quantified using a GeneQuant $^{\mathrm{TM}} 1300$ spectrophotometer (Biochrom Ltd, Cambridge, UK). $1 \mu \mathrm{g}$ RNA was reverse transcribed using the PrimeScript $^{\mathrm{TM}}$ 1st Strand cDNA Synthesis Kit (Takara). PCR reactions were carried out using specific primers PsF: 5'GGAGGACCACCTTCGC ATC-3' and PsR: 5'GTACATCTCCTTAACGGCAT-3'. 18s rRNA for ribosomal RNA gene was amplified as an internal control using the primers PsFa: 5'-CGCTACACTGAAGG AATC-3' and PsFb: 5'-GTCCGAAGACCTCACTAAAT-3'. PCR reactions were carried out for 35 cycles with an optimal annealing temperature of $56^{\circ} \mathrm{C}$ along with appropriate control reactions. All RT-PCR reactions were replicated five times.

\section{Enzyme activity assay}

Midguts were taken from adult beetles and treated according to Mao et al. (2007). The homogenates were centrifuged $(12,000$ $\mathrm{rpm})$ for $30 \mathrm{~min}$ at $4^{\circ} \mathrm{C}$ to obtain a crude enzyme solution. The amount of protein was determined using the Coomassie Blue $\mathrm{G}$ dye assay. The standard sample of arginine kinase was purchased from Sigma Ltd (UK). Arginine kinase activity was assayed according to Sigma's product instruction manual (Product No. A3389). One Unit of the enzyme was defined as $1.0 \mu$ mole of L-arginine and ATP converted to N-phospho-Larginine and ADP per minute at $\mathrm{pH} 8.6$ and $30^{\circ} \mathrm{C}$.

\section{RESULTS AND DISCUSSION}

The full-length (1508 bp) of the PsAK gene, containing a $51 \mathrm{bp}$ of 5 ' untranslated region (UTR), $1071 \mathrm{bp}$ of open reading frame (ORF) and 386 bp of 3' UTR, was successfully amplified using PCR. The ORF begins with an ATG initiation codon at nucleotide 52 and terminates with a TAA at nucleotide 1122 (Fig. 2). A putative polyadenylation signal AATAAA was recognized at the nucleotide position 1445, which is 28 nucleotides upstream of the poly(A) tail. Five glycol motifs (AAYNNNAC) and three putative ribosomal binding site motifs (AGGAGG) were discovered by sequence analysis. The cDNA sequence was deposited in GenBank under accession no. EU420057. The ORF encodes a polypeptide of 356 amino acids with most of the residues considered necessary for AK's enzymatic function. Its theoretical mass is 40016.43 Da with an estimated isoelectric point of 5.86, which are in the agreement with the results of other recent studies (Wang \& Xu, 2006; Yao et al., 2005). In addition, the highly conserved motif CPTNLGT (positions 271-277) around a reactive cysteinyl residue (position 271 ) is the signature pattern for this family of arginine kinase. The well-conserved Cys 271, which plays an important role in substrate binding, was recently demonstrated by site directed mutagenesis to be directly involved in AK catalysis reaction (Gattis et al., 2004). PsAK also contains two highly conserved amino acids, Asp 62 and Arg 193, that are responsible for the synergism in the substrate binding of AK (Zhou et al., 1998). The distance between the $\mathrm{OD}_{2}$ atom of Asp 62 and the $\mathrm{NH}_{2}$ atom of Arg 193 is only $2.86 \AA$ in our 3-D model of the structure. This short distance can form a strong hydrogen bond, which results in strong electrastatic interaction stabilizing the closed substrate-bound structure of PsAK.

The cDNA-derived amino acid sequence of PsAK shows 66-91\% amino acid sequence identity with the AKs of other insects (Fig. 3). It is evident that the amino acid sequence of PSAK is more similar to that of Tribolium castaneum $\mathrm{AK}$ (Coleoptera) than that of $\mathrm{AKs}$ in other insects. It should be noted that the sequence identities of insect Aks, excluding Cissites cephalotes $\mathrm{AK}$ (CcAK), are rather high (82-91\%). On the distance tree most of the insect families are clustered together (Fig. 4). Surprisingly, the CcAK, belonging to the coleopteran family, shows obvious differences from that of other insect AKs. The distance tree clearly indicates that insect AKs separate into two groups: Group 1 consists of typical AKs from various insect species and PsAK also belongs to this group; Group 2 only includes $\mathrm{CcAK}$, which accords with Tanaka's study. Tanaka et al. (2007) thought CcAK was expressed in insects.

AK plays a critical role in cell energy metabolism in invertebrates and, therefore, seems to be an excellent target for RNAi, which would result in an increase in the morbidity and mortality of insects. We, therefore, selected a conserved domain consisting of a $332 \mathrm{bp}$ fragment (nucleotides 790 to 1122) of PsAK containing the active site motif CPTNLGT to obtain the dsRNA (Fig. 2). The 
A

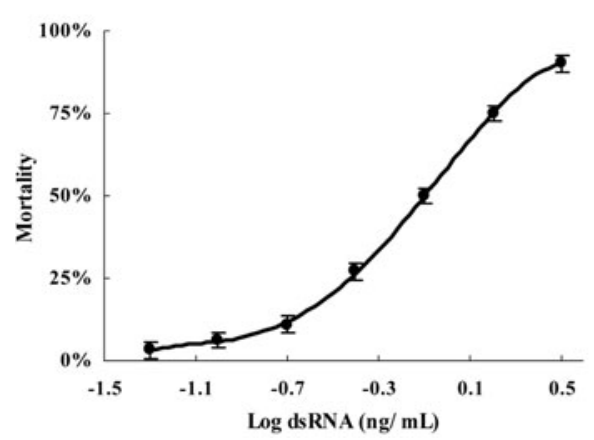

B

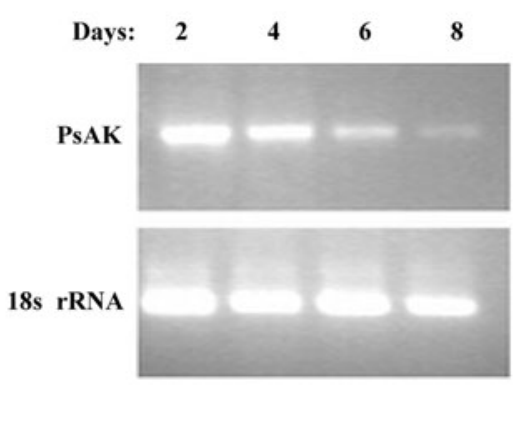

C

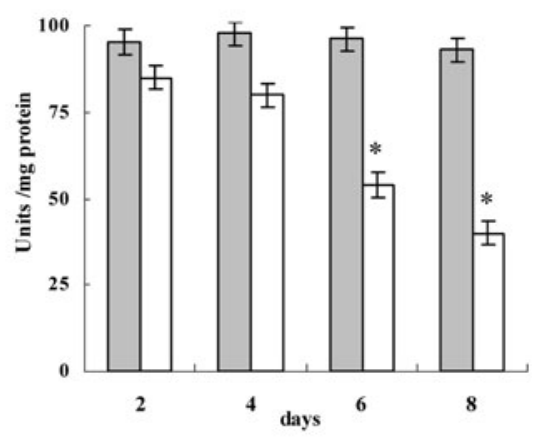

Fig. 5. (A) Concentration-dependent mortality associated with the ingestion of dsRNAs. The two-fold dilutions of dsRNA were tested and the assays scored after 14 days to determine LC50 value. LC50 value: $0.80 \mathrm{ng} / \mathrm{mL}(P<0.05)$. (B) Suppression of AK mRNA transcripts level in midguts of adult beetles fed on $0.80 \mathrm{ng} / \mathrm{mL}$ dsRNA. The mRNA abundance was determined by RT-PCR analysis and 18s rRNA for ribosomal RNA gene was amplified as an internal control. (C) Enzyme activity of AK in midguts reflecting RNAi effects at different times after adult beetles were fed $0.80 \mathrm{ng} / \mathrm{mL}$ dsRNA $\left({ }^{*} P<0.05\right)$. One Unit of the enzyme was defined as $1.0 \mu$ mole of L-arginine and ATP converted to N-phospho-L-arginine and ADP per minute at a $\mathrm{pH} 8.6$ and $30^{\circ} \mathrm{C}$.

quality and integrity of the dsRNA was verified by agarose gel electrophoresis. Equal numbers of both sexes of similar aged beetles were fed on seedlings of Chinese cabbage sprayed with dsRNA solutions.

To quantify the activity of the dsRNA more precisely, a range of dsRNA dilutions from 0.05 to $3.20 \mathrm{ng} / \mathrm{mL}$ were used to obtain the LC50 value. Initially, feeding dsRNA had no visible effect on the adult beetles. However, on day 14 over $90 \%$ of the adults fed dsRNA $3.20 \mathrm{ng} / \mathrm{mL}$ were dead. The concentration-response curve is shown in Fig. 5A, where the dots represent the percentage mortality recorded after 14 days when fed dsRNA ranging in concentration from 0.05 to $3.20 \mathrm{ng} / \mathrm{mL}$. The LC50 value of this response curve is $0.80 \mathrm{ng} / \mathrm{mL}(P<0.05)$.

To determine the adverse effects of dsRNA on $P$. striolata, adult beetles were grouped and fed a range of dilutions of dsRNA, from 0.05 to $1.60 \mathrm{ng} / \mathrm{mL}$. Because this beetle normally lives for 24 to 48 days, 30 days was used as the observation period. Fig. 6 shows the percentage survival, number of eggs laid per female and percentage egg hatch compared to that recorded for the control group (Control: dsRNA $0 \mathrm{ng} / \mathrm{mL})$ after 30 days $(P<0.05)$. In the control group, over $90 \%$ of the adults survived for 30 days; the female laid an average of 49 eggs per female and $74 \%$ of the eggs hatched. Both number of the eggs laid per female and percentage egg hatch were lower than that recorded in the field. However, there were significant differences between the experimental and control groups $(P<0.05)$. The survival of adults in the experimental groups decreased from $85 \%$ to $15 \%$ when fed dsRNA ranging in concentration from 0.05 to $1.60 \mathrm{ng} / \mathrm{mL}$ (Fig. $6 \mathrm{~A}$ ), which is dramatically lower than that recorded in the control group $(P<0.05)$. Likewise, the mean number eggs laid per female ranged from 41 to 7 eggs when fed dsRNA ranging in concentration from 0.05 to $1.60 \mathrm{ng} / \mathrm{mL}$ (Fig. 6B). The significant effect of dsRNA on percentage egg hatch is seen in Fig. 6C, with less than $13 \%$ of the eggs laid by beetles fed $1.60 \mathrm{ng} / \mathrm{mL}$ dsRNA hatching. The above results demonstrate that minute quantities of dsRNA targeting AK can adversely affect this beetle causing a reduction in growth, survival, fecundity and fertility.

To confirm that the ingestion of dsRNA triggered a specific silencing in adult beetles, the total RNA from the midguts of dsRNA-fed and dsRNA untreated adults was determined using RT-PCR analysis in order to demonstrate the down regulation of the specific target gene (Fig. 5B). Adults fed on seedlings treated with AK dsRNA $(0.80 \mathrm{ng} / \mathrm{mL})$ exhibited a significant decrease in endogenous AK mRNA compared to the controls. The suppression of AK mRNA at the transcription level was recorded by the RT-PCR. The midguts of beetles that ingested dsRNA displayed a gradual decrease in AK mRNA over the course of 8 days. In contrast, the levels of AK mRNA remained the same in the midguts of the control beetles.

As the negative effect on AK enzyme activity is likely to be magnified if AK transcripts levels are down regulated by RNAi, the AK activity was analyzed using a NADH-Linked enzyme assay (Fig. 5C). The level of AK activity over 8 days in the experimental group fed 0.80 $\mathrm{ng} / \mathrm{mL}$ was significantly attenuated compared to that in the controls. During the first 4 days, the inhibition of AK activity was very slight, and enzyme activity remained at more than $80 \%$. However, on the 6th day the miguts of beetles fed dsRNA showed a loss of nearly one-half in the catalytic activity of this protein $\left({ }^{*} P<0.05\right)$, whereas there was no change in the control group. That is, the adverse effect on growth and increase in mortality in the experimental group became apparent after one week.

RT-PCR and enzyme assays provide molecular evidence of a link between the silencing of AK and the poor growth and increase in mortality of the beetle. There was a time-lag between gene silencing and adult death. An interesting question is whether RNAi amplifies and affects cells other than gut epithelial cells. The requirement for RNAi amplification and systemic spread could account in part for the time-lag between gene silencing and beetle death. Minute amounts of dsRNA ingested by the nematode, Caenorhabditis elegans, trigger systemic silencing driven by core RNAi genes, such as RNA- 
A

B

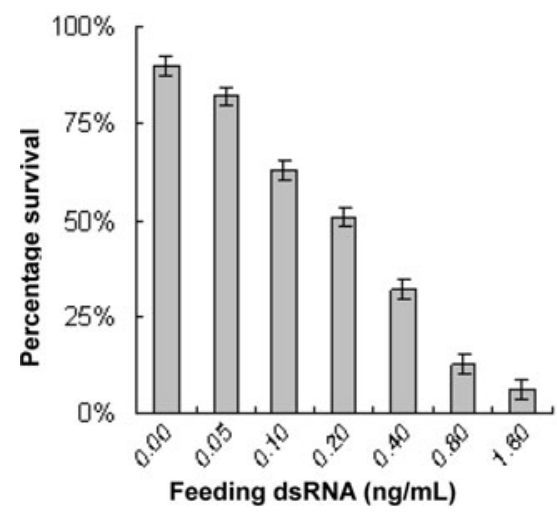

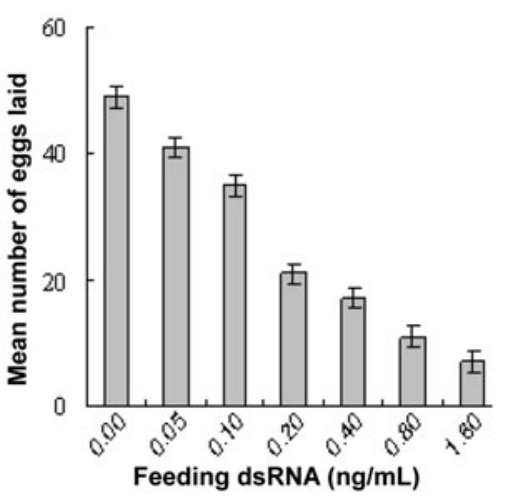

C

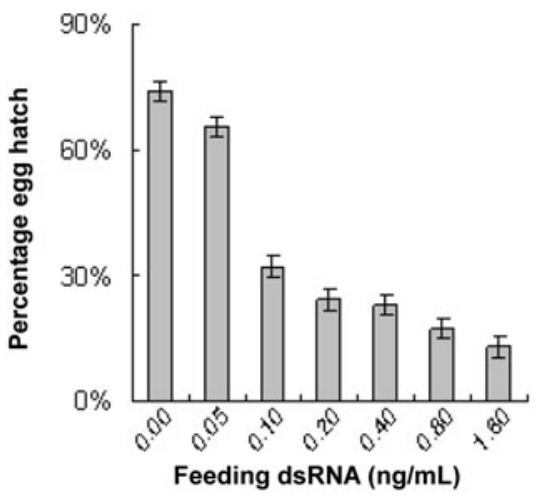

Fig. 6. The effects of feeding dsRNA on the life cycle of $P$. striolata, in which the results of dsRNA untreated group (dsRNA 0.00 $\mathrm{ng} / \mathrm{mL})$ and experimental groups fed a range of dilutions of dsRNA from 0.05 to $1.60 \mathrm{ng} / \mathrm{mL}$ were compared after one month $(P<$ 0.05), (A) The percentage survival (B) Mean number of eggs laid (C) Percentage egg hatch.

dependent RNA polymerase (RdRP) and RNA channel transporter SID (Fire et al., 1998; Winston et al., 2002). However, insects apparently lack RdRP. In a recent survey of systemic RNAi in T. castaneum, three putative SID-like genes were identified, but they do not seem to be required for systemic RNAi (Tomoyasu et al., 2008). Thus systemic RNAi in insects might be based on a different mechanism, which needs to be elucidated. Understanding the molecular mechanisms may facilitate the application of RNAi techniques in pest control.

An aspect of AK dsRNA important for pest control is that it can be directly sprayed onto crops, which has potential commercial implications. Previous studies indicate that dsRNA molecules are highly stable in vitro and can persist on the leaves for several days (Tenllado \& Diaz-Ruiz, 2001). Thus RNAi technology could be deployed in the field. However, there are barriers to oral administration. For instance, the larvae of $P$. striolata live in the soil and eat the roots of seedlings. Spraying dsRNA onto the leaves of seedlings has no apparent toxic effects on the beetle larvae.

An important question arising from this study is whether other insect species will be affected by the application of dsRNA targeting PsAK. Baum et al. (2007) report that Diabrotica virgifera larvae are killed when fed an artificial diet containing specific dsRNAs designed to target $D$. virgifera genes. When these dsRNAs targeting $D$. virgifera genes were tested on other insect pests, mortality declined with decrease in sequence identity between the $D$. virgifera genes and their orthologs in the other insect species tested. Because the AK gene is highly conserved in insects, and PSAK has a similar sequence identity in other insect species, then dsRNA targeting PsAK could potentially adversely affect other insects and be used as a general biocontrol agent for pests. This study demonstrated that dsRNA targeting PsAK is effective at killing $P$. striolata adults. Further experiments are necessary to determine the effectiveness of dsRNA targeting AK in controlling other insect species. Whether the selec- tivity of the gene silencing depends only on nucleotidesequence identity needs further investigation.

Another question that arises from this study is the cost of commercially applying dsRNA products. To use genetically engineered plants to deliver dsRNA is a very promising strategy, but it has some drawbacks and requires improvement. First of all, transgenic plants do not normally produce sufficient dsRNA due to the expression of heterologous genes derived from different backgrounds in plants (Kusnadi et al., 1997; Teli \& Timko, 2004); Secondly, Dicer-like enzymes are ubiquitously generated in plants, which may degrade the intact dsRNA and therefore weaken its efficacy against insects (Xie et al., 2004; Bouche et al., 2006; Gordon \& Waterhouse, 2007). Thirdly, transgenic plants express dsRNA throughout their entire life. Because insect populations are thus exposed to continuous selection pressure, they are likely to eventually develop resistance. Compared to producing transgenic plants, direct spraying of dsRNA onto plant leaf surfaces is very simple and fast, but in vitro biosynthesis of dsRNA is still relatively expensive. Currently, our group is in the process of developing an in vivo system for producing large amounts of dsRNAs in RNase III-deficient bacteria, which will greatly reduce the cost of production.

Last but not the least is how the internal defense mechanism of the beetle will respond to long-term exposure to dsRNA. It is unknown whether the beetles (as a "population") will eventually overcome the detrimental effects of the AK inhibition, or develop some "rescue" pathway. Thus, further experiments are needed as well as a more detailed knowledge of the sequence variation in the population (Karl Gordon, pers. commun.). There are no publications on this aspect of the problem at present, but will become available in the future, partly provided by the genome sequencing and downstream gene expression profiling.

In summary, we cloned and characterized the AK gene from $P$. striolata and used dsRNA in feeding experiments to control this beetle. The results indicate that RNAi tar- 
geting AK can be an effective method of controlling this insect pest and may also be suitable for controlling other insect pests.

ACKNOWLEDGEMENTS. This research was supported by the following Grants: "National Key Basic Research Project" (2006 CB100204), "International Co-operation Fund" (2003DF03008), and "The Key Basic Research Project in Fujian Province" (B0520003). Y.Y. Zhao thanks DAAD for providing her a stipendium.

\section{REFERENCES}

Andersen C.L., Hazzard R., Van Driesche R. \& Mangan F.X. 2006: Alternative management tactics for control of Phyllotreta cruciferae and Phyllotreta striolata (Coleoptera: Chrysomelidae) on Brassica rapa in Massachusetts. J. Econ. Entomol. 99: 803-810.

Baum J.A., Bogaert T., Clinton W., Heck G.R., Feldmann P., Ilagan O., Johnson S., Plaetinck G., Munyikwa T., Pleau M., Vaughn T. \& RoberTs J. 2007: Control of coleopteran insect pests through RNA interference. Nat. Biotech. 25: 1322-1326.

Bettencourt R., Terenius O. \& Faye I. 2002: Hemolin gene silencing by dsRNA injected into Cecropia pupae is lethal to next generation embryos. Insect Mol. Biol. 11: 267-271.

Bouche N., Lauressergues D., Gasciolli V. \& Vaucheret H. 2006: An antagonistic function for Arabidopsis DCL2 in development and a new function for DCL4 in generating viral siRNAs. EMBO J. 25: 3347-3356.

Brown A.E. \& Grossman S.H. 2004: The mechanism and modes of inhibition of arginine kinase from the cockroach (Periplaneta americana). Arch. Insect Biochem. 57: 166-177.

ChAMBERLIN M.E. 1997: Mitochondrial arginine kinase in the midgut of the tobacco hornworm. J. Exp. Biol. 200: 2789-2796.

ELLINGTON W.R. 2001: Evolution and physiological roles of phosphagen systems. Annu. Rev. Physiol. 63: 289-325.

Fire A., Xu S., Montgomery M.K., Kostas S.A., Driver S.E. \& Mello C.C. 1998: Potent and specific genetic interference by double-stranded RNA in Caenorhabditis elegans. Nature 391: 806-811.

Ghanima M., Kontsedalov S. \& Czosnek H. 2007: Tissuespecific gene silencing by RNA interference in the whitefly Bemisia tabaci (Gennadius). Insect Biochem. Mol. Biol. 37: 732-738.

Gordon K.H. \& WAterhouse P.M. 2007: RNAi for insect-proof plants. Nat. Biotech. 25: 1231-1232.

KuChaRsKi R. \& MALEszKa R. 1998: Arginine kinase is highly expressed in the compound eye of the honeybee, Apis mellifera. Gene 211: 343-349.

Kusnadi A.R., NiKolov Z.L. \& Howard J.A. 1997: Production of recombinant protein in transgenic plants: practical considerations. Biotechnol. Bioeng. 56: 473-483.

LANG A.B., Wyss C. \& Eppenberger H.M. 1980: Localization of arginine kinase in muscle fibres of Drosophila melanogaster. J. Muscle Res. Cell Motil. 1: 147-161.

Mao Y.B., CaI W.J., Wang J.W., Hong G.J., Tao X.Y., Wang L.J., HuAng Y.P. \& CHEN X.Y. 2007: Silencing a cotton bollworm P450 monooxygenase gene by plant-mediated RNAi impairs larval tolerance of gossypol. Nat. Biotech. 25: $1307-1313$.

Newsholme E.A., Beis I., Leech A.R. \& Zammit V.A. 1978: The role of creatine kinase and arginine kinase in muscle. Biochem. J. 172: 533-537.

Pereira C.A., Alonso G.D., Paveto M.C., Tribarren A., Cabanas M.L., Torres H.N. \& Flawiá M.M. 2000: Trypano- soma cruzi arginine kinase characterization and cloning. $J$. Biol. Chem. 275: 1495-1501.

Pereira C.A., Alonso G.D., Ivaldi S., Bouvier L.A., Torres H.N. \& Flawí́ M.M. 2003: Screening of substrate analogs as potential enzyme inhibitors for the arginine kinase of Trypanosoma cruzi. J. Eukaryot. Microbiol. 50: 132-134.

RoSENTHAL G.A. 2001: L-Canavanine: a higher plant insecticidal allelochemical. Amino Acids 21: 319-30.

Tanaka K., Ichinari S., Iwanami K., Yoshimatsu S. \& Suzuki T. 2007: Arginine kinase from the beetle Cissites cephalotes (Olivier): Molecular cloning, phylogenetic analysis and enzymatic properties. Insect Biochem. Mol. Biol. 37: 338-345.

Teli N.P. \& Timko M.P. 2004: Recent developments in the use of transgenic plants for the production of human therapeutics and biopharmaceuticals. Plant Cell Tiss. Organ. Cult. 79: 125-145.

Tenllado F. \& Diaz-Ruiz J.R. 2001: Double-stranded RNAmediated interference with plant virus infection. J. Virol. $\mathbf{7 5}$ : 12288-12297.

Tenllado F., Barajas D., Vargas M., Atencio F.A., GonzálezJARA P. \& DíAZ-Ruíz J.R. 2003a: Transient expression of homologous hairpin RNA causes interference with plant virus Infection and is overcome by a virus encoded suppressor of gene silencing. Mol. Plant Microbe Interact. 16: 149-158.

Tenllado F., Martínez-García B., Vargas M. \& Díaz-Ruíz J.R. 2003b: Crude extracts of bacterially expressed dsRNA can be used to protect plants against virus infections. BMC Biotechnol. 3(3): 1-11.

Tomoyasu Y. \& Denell R.E. 2004: Larval RNAi in Tribolium (Coleoptera) for analyzing adult development. Dev. Genes Evol. 214: 575-578.

Tomoyasu Y., Miller S.C., Tomita S., Schoppmeier M., GrossMANN D. \& BUCHER G. 2008: Exploring systemic RNA interference in insects: a genome-wide survey for RNAi genes in Tribolium. Genome Biol. 9(1): R10.

Turner C.T., Davy M.W., MacDiarmid R.M., Plummer K.M., BIRCH N.P. \& Newcomb R.D. 2006: RNA interference in the light brown apple moth, Epiphyas postvittana (Walker) induced by double-stranded RNA feeding. Insect Mol. Biol. 15: 383-391.

WANG H.B. \& XU Y.S. 2006: cDNA cloning, genomic structure and expression of arginine kinase gene from Bombyx mori (L.), Sci. Agric. Sin. 39: 2354-2361 [in Chinese, English abstr.].

Winston W.M., Molodowitch C. \& Hunter C.P. 2002: Systemic RNAi in C. elegans requires the putative transmembrane protein SID-1. Science 295: 2456-2459.

Wu Q.Y., Li F., Zhu W.J. \& Wang X.Y. 2007: Cloning, expression, purification, and characterization of arginine kinase from Locusta migratoria manilensis. Comp. Biochem. Physiol. (B) 148: 355-362.

Xie Z., Johansen L.K., Gustafson A.M., Kasschau K.D., Lellis A.D., Zilberman D., Jacobsen S.E. \& Carrington J.C. 2004: Genetic and functional diversification of small RNA pathways in plants. PLoS Biol. 2(5): E104.

Yao C.L., Wu C.G., Xiang J.H. \& Dong B. 2005: Molecular cloning and response to laminarin stimulation of arginine kinase in haemolymph in Chinese shrimp, Fenneropenaeus chinensis. Fish Shellfish Immunol. 19: 317-329.

Zhou G., Somasundaram T., Blanc E., Parthasarathy G., Ellington W.R. \& Chapman M.S. 1998: Transition state structure of arginine kinase: implications for catalysis of bimolecular reactions. Proc. Natl. Acad. Sci. USA 95: 8449-8454.

Received April 10, 2008; revised and accepted June 16, 2008 